\title{
New insights into patterns of first metastatic sites influencing survival of patients with hormone receptor-positive, HER2-negative breast cancer: a multicenter study of 271 patients
}

Jun Yamamura ( $\nabla$ june10th68@gmail.com )

Sakai City Medical Center https://orcid.org/0000-0002-5540-7348

Shunji Kamigaki

Sakai City Medical Center

Junya Fujita

Sakai City Medical Center

Hiroki Osato

Sakai City Medical Center

Hironobu Manabe

Kindai University Faculty of Medicine

Yumiko Tanaka

Kindai University Faculty of Medicine

Wataru Shinzaki

Kindai University Faculty of Medicine

Yukihiko Hashimoto

Kindai University Faculty of Medicine

Yoshifumi Komoike

Kindai University Faculty of medicine

Research article

Keywords: Breast cancer, recurrence, survival, hormone receptor-positive, HER2-negative, metastatic pattern

Posted Date: November 3rd, 2020

DOl: https://doi.org/10.21203/rs.3.rs-20043/v2

License: (c) (1) This work is licensed under a Creative Commons Attribution 4.0 International License. Read Full License 
Version of Record: A version of this preprint was published at BMC Cancer on April 29th, 2021. See the published version at https://doi.org/10.1186/s12885-021-08219-3. 


\section{Abstract}

Background: The initial therapeutic strategy for hormone receptor-positive (HR+), HER2-negative (HER2-) breast cancer is based on the first metastatic site, but little evidence is available regarding the influence of metastatic distribution patterns of first metastatic sites on prognosis. In this study, we aimed to identify the metastatic distribution patterns of first metastatic sites that significantly correlate with survival after recurrence.

Methods: We performed a retrospective review of records from 271 patients with recurrent metastatic HR+/ HER2- breast cancer diagnosed between January 2000 and December 2015. We assessed survival after recurrence according to the metastatic distribution patterns of first metastatic sites and identified significant prognostic factors among the patients with single and multiple metastases.

Results: Prognosis was significantly better in patients with single metastasis than those with multiple metastases (median overall survival after recurrence: 5.86 years vs. 2.50 years, $p<0.001$ ). No metastatic organ site with single metastasis was significantly associated with prognostic outcome, though single metastasis with diffuse lesions was an independent risk factor for worse prognosis (HR: $3.641 ; 95 \% \mathrm{Cl}$ : 1.856-7.141), and more easily progressed to multiple metastases $(p=0.002)$. Multiple metastases including liver metastasis (HR: $3.145 ; 95 \%$ Cl: $1.802-5.495)$ or brain metastasis (HR: $3.289 ; 95 \%$ Cl: $1.355-$ 7.937) were regarded as a significant independent poor prognostic factor, but multiple metastases not involving liver or brain metastasis were not significantly related to prognosis after recurrence.

Conclusions: Single metastasis with diffuse lesions could more easily disseminate systemically and progress to multiple metastases, leading to poor prognosis similar to multiple metastases. Our findings indicate that reconsideration of the determinant factors of therapeutic strategies for first recurrence in HR+/HER2- breast cancer may be needed.

\section{Introduction}

Breast cancer is the most commonly diagnosed cancer in women and a leading cause of cancer-related mortality worldwide [1, 2]. Despite recent improvements in adjuvant treatment, $20-30 \%$ of early breast cancer patients will develop distant metastasis and be generally incurable, in which cases the main treatment goal is symptom palliation [3-5]. And, more than $70 \%$ of the patients present with hormone receptor-positive (HR+), human epidermal growth factor receptor 2-negative (HER2-) breast cancer [6]. According to current guidelines and international consensus statements, the metastatic patterns of first metastatic sites are important determinants of the initial therapeutic strategy for HR+/HER2- metastatic patients [7-9]. However, the metastatic patterns of first metastatic sites, such as multiple metastases, immediately life-threatening disease, or rapidly progressive visceral metastasis or crisis, have not been clearly evaluated. Although previous real-world studies have demonstrated several significant prognostic factors of survival after recurrence [10-24], little regard has been given to the influence of the metastatic distribution patterns of first metastatic sites on patients' prognosis. We assumed that the metastatic 
distribution patterns should be analyzed in more detail for the relationship with survival after recurrence in HR+/HER2- patients. Therefore, we used the clinical data of HR+/HER2- recurrent breast cancer patients with distant metastasis to identify the correlation between the metastatic distribution patterns of first metastatic sites and survival after recurrence by evaluating the prognosis of each HR+/HER2- patient with single and multiple metastases separately. We also classified single metastasis into diffuse lesions and non-diffuse lesions, which may help us determine more beneficial therapeutic strategies and meet the unmet needs of these patients. A deeper understanding of the metastatic distribution pattern in HR+/HER2- patients may be needed for the delivery of appropriate healthcare to poor-prognosis groups and play an important role in optimal treatment and care, improving the prognosis of these metastatic patients.

\section{Methods}

\section{Study design and patients}

This study was conducted using a retrospective longitudinal cohort design, with use of hospital electronic patients records. Patients with a first diagnosis of recurrent HR+/HER2- breast cancer made between January 2000 and December 2015 were identified from Sakai City Medical Center and Kindai University Hospital. Patients treated within a clinical trial (prior to or during the study period) were excluded. Index date was that of first diagnosis as distant recurrent breast cancer. Follow-up was defined as the interval between index date and the confirmed date of death, the censored date (if lost to follow-up) or the study end in December 2018. According to current guidelines, all patients received standard adjuvant treatment and were followed through regular physical examination 1-4 times a year and annual mammography, and if necessary, blood exam, ultrasonography, computed tomography (CT), bone scintigraphy, magnetic resonance imaging or position emission tomography/CT were added for diagnosis of recurrence. Recurrence was defined as the occurrence of a distant metastasis after removal of the primary breast cancer. Patients with only locoregional recurrence and distant metastasis at initial diagnosis (de novo Stage IV metastatic disease) were excluded from this analysis. Ipsilateral breast tumor recurrence and ipsilateral axillary, inflaclavicular, internal mammary, and supraclavicular lymph node metastasis were defined as locoregional recurrence. TNM staging was based on the criteria of the 8th Union for International Cancer Control. The adjuvant and metastatic treatment strategies (treatment protocol after recurrence) were all decided at the experts' conference in the institutions based on current guidelines. This study was approved by the institutional review board of the two hospitals and all enrolled patients provided informed consent.

\section{Immunohistochemical and serological assay}

Positivity for estrogen receptor (ER) or progesterone receptor (PR) was defined as a score $\geq 3$ using the Allread scoring system [25]. HR-positivity was defined as ER and/or PR-positivity. HER2-negativity was defined as an immunohistochemistry score of $0,1+$, or $2+$ and negative fluorescence in situ hybridization 
(ratio <2.0). The concentration of serum carcinoembryonic antigen (CEA) and cancer antigen 15-3 (CA153) levels were measured at the first distant recurrence using an electrochemiluminescent immunoenzymometric assay (Roche Diagnostics, Tokyo, Japan). The upper limits of normal for CEA and CA15-3 were $5 \mathrm{ng} / \mathrm{ml}$ and $25 \mathrm{U} / \mathrm{ml}$, respectively.

\section{Metastatic distribution patterns of first metastatic sites}

The first metastatic sites were classified into single metastasis or multiple metastases, and furthermore, single metastasis was classified into diffuse lesions or non-diffuse lesions. Non-diffuse lesions were defined as localized or focal lesions in a single metastatic organ or site regardless of size, whereas diffuse lesions were defined as multiple lesions widely spreading in a single metastatic organ or site. Non-diffuse lesions include a solitary metastatic lesion in one single organ (e.g. a solitary lung metastasis), involvement of a single lymphathic site (e.g. a ipsilateral hilar lymph node metastasis) , or a solitary or isolated metastatic bone lesion. On the other hand, diffuse lesions include multiple lesions in one single organ (e.g. multiple lung metastases), involvement of two or more lymphatic sites (e.g. bilateral hailar lymph node metastases), multiple metastatic bone lesions, or pleural or peritoneal dissemination.

\section{Survival outcomes}

Overall survival (OS) was defined as the time from the date of the first distant recurrence to the time of death or last follow-up. The disease-free interval (DFI) was defined as the interval between the diagnosis of the primary non-metastatic breast cancer and the date of the first distant recurrence. Time to multiple metastases (TTM) was defined as the time from the date of the first distant recurrence at a single metastatic site to the date of the progression of disease at multiple metastatic sites.

\section{Statistical analysis}

OS plots were created using the Kaplan-Meier method, and the distributions of the survival curves were compared using log-rank tests. The Cox proportional hazard regression model was used to examine the prognostic evaluation between the groups using several prognostic indicators, including patient and disease-related clinicopathological factors, and metastatic organ sites and distribution patterns. A 95\% confidence interval $(\mathrm{Cl})$ was calculated for all hazard ratios (HRs) in the Cox regression analysis. We evaluated the results of the univariate and multivariate Cox proportional hazards model with hazards ratios $>1.0$ indicating an increased risk of death. All tests were two-tailed, and $p$-values $<0.05$ were considered significant. Statistical analyses were performed using the statistical software package SPSS (v.17.0; Chicago, IL, USA).

\section{Results}

\section{Patient characteristics}


Our analysis included 271 patients with recurrent metastatic HR+/HER2- breast cancer during the study period. The median follow-up for our sample was 8.57 years (range, 1.05-19.67). Patients characteristics for the study cohort are summarized in Table 1. Median age at recurrence was 62 years (range, 29-92). Majority were patients with single metastasis $(n=169,62 \%)$, and bone was the most common metastatic organ site $(n=148,55 \%)$ of all patients.

\section{Survival outcomes}

The median OS after recurrence estimated according to patient characteristics is given in Table 2. The median OS after recurrence for patients with single metastasis and multiple metastases was 5.86 and 2.50 years, respectively $(p<0.001 ;$ Fig. 1$)$. Of the patients with single metastasis, those with high serum levels of CEA/CA15-3 ( $p=0.014$; Fig. 2a), shorter DFI ( $<2$ years, $p<0.001$; Fig. $2 \mathbf{b}$ ), or diffuse lesions had significantly worse prognosis $(p<0.001 ; \mathrm{Fig} .2 \mathrm{c})$, whereas any metastatic organ site with single metastasis was not significantly associated with prognostic outcomes. Of the patients with multiple metastases, patients with shorter DFI, liver metastasis, or brain metastasis had significantly worse prognosis, but multiple metastases not involving liver or brain metastasis had no significant relationship with prognostic outcomes.

\section{Univariate and multivariate analysis of factors related to survival after recurrence}

The multivariate analysis was performed according to the prognostic factors that were significant in the univariate analysis in patients with single metastasis and multiple metastases. The multivariate analysis revealed two significantly independent prognostic factors related to poor survival after recurrence in patients with single metastasis: shorter DFI and diffuse lesions (Table 3). The multivariate analysis revealed three significantly independent prognostic factors related to poor survival after recurrence in patients with multiple metastases: shorter DFI, liver metastasis, and brain metastasis (Table 4).

\section{TTM for diffuse lesions and non-diffuse lesions}

Survival plots showed that TTM was significantly shorter for patients with diffuse lesions among those with single metastasis compared to those with non-diffuse lesions (median TTM: 24.2 months vs. 52.0 months, $p=0.002$; Fig. 3).

\section{Discussion}

Metastatic breast cancer represents a biologically heterogeneous population with diverse metastatic patterns exhibiting highly unpredictable clinical behaviors [26-28]. Prognosis varies significantly among patient subtypes [29,30], and several concepts regarding the prognosis of HR+/HER2- metastatic patients have been considered important in evaluating survival after recurrence [11]. Previous studies have shown that first metastatic sites (single, multiple, liver, or other visceral metastases) are significantly related to survival after recurrence in HR+/HER2- patients [10-13], but there has been clinical diversity in the metastatic distribution patterns of both single metastasis and multiple metastases [26-28]. Therefore, we 
studied the prognosis of HR+/HER2- patients with single and multiple metastases separately, especially based on the metastatic distribution patterns.

Multiple metastases are considered a poor prognostic factor [10-18]. The prognosis of patients with multiple metastases may vary with the metastatic organ sites due to the heterogeneity [26-28], but there has been no report investigating prognosis by each relevant metastatic organ site involved in multiple metastases. In the current study, multiple metastases including liver or brain metastasis was a strong independent prognostic factor for worse outcomes in HR+/HER2- patients, whereas multiple metastases not involving liver or brain metastasis had no significant relationship with prognosis after recurrence. This finding supports the assumption that multiple metastases involving liver or brain metastasis is indicative of extensive spreading or dissemination of cancer cells, or lethal organ dysfunction, leading to poor survival outcomes $[11,15,24]$. In real-world practice, patients with multiple metastases are more likely to receive cytotoxic therapy because their vital organs are potentially damaged or in "visceral crisis" [19-21]. However, not all multiple metastases may lead to poor outcomes due to their own heterogeneity [19]; therefore, we should determine the most reliable and decisive prognostic factors for HR+/HER2patients with multiple metastases.

Single metastasis has been regarded as a better prognostic factor than multiple metastases due to the probability of less tumor burden than with multiple metastases [10-18]. However, most patients with single metastasis will eventually develop multiple metastases, finally leading to poor outcomes. In this study, we analyzed the prognosis of patients with single metastasis by classifying single metastasis into diffuse lesions and non-diffuse lesions. To the best of our knowledge, this is the first study to investigate the prognosis of patients with single metastasis based on the metastatic distribution patterns between diffuse and non-diffuse lesions, and to evaluate the time to dissemination of single metastasis to multiple metastases. We found that diffuse lesions in single metastasis were independently related to worse prognosis and easier systemic dissemination to multiple metastases. Diffuse lesions in single metastasis may likely behave as multiple metastases due to the dissemination potential. According to traditional guidelines [7-9], non-cytotoxic therapy is indicated as first-line treatment for HR+/HER2patients with single metastasis. Thus, our study suggests reconsidering the therapeutic guidelines, and additional treatment strategies should be demanded for patients with diffuse lesions in single metastasis. Our proposal may meet the unmet need for more efficacious treatments for HR+/HER2patients with diffuse lesions in single metastasis. The initial use of more advantageous treatments, including novel targeted agents [31], could provide more beneficial effects and support better prognoses for these patients.

Our study had some limitations. First, our study was performed as a retrospective chart review without validation, and sampling biases may not have been avoidable. Second, the sample size of our study was small, and our results should be interpreted with caution. However, the selection of patients with HR+/HER2- recurrent breast cancer and exclusion of HER2+, triple-negative, and de novo breast cancer patients may have allowed the recruitment of a patient population with relative homogeneity. Future studies with a larger cohort of patients may yield more conclusive evidence of the prognostic findings in 
this study. Despite these limitations, the current study with a uniform population provides important insights about the real-world clinical outcomes for patients with recurrent metastatic HR+/HER2- breast cancer.

\section{Conclusion}

Our study presents new evidence of metastatic patterns and real-world clinical outcomes for HR+/HER2recurrent metastatic breast cancer. We confirmed that multiple metastases not involving liver or brain metastasis had no significant relationship with prognosis after recurrence, and that single metastasis with diffuse lesions was an independent factor for worse prognosis, with easier systemic dissemination and progression to multiple metastases than non-diffuse lesions. These findings may require reconsideration of the determinants of initial therapy for HR+/HER2- recurrent metastatic breast cancer and provide frontline physicians with new important clinical clues to achieve optimal treatment, leading to effective therapeutic strategies to improve the prognosis of this metastatic disease.

\section{Declarations}

\section{Acknowledgement}

Not applicable.

\section{Funding}

Not applicable.

\section{Availability of data and materials}

The datasets used and analyzed during this study are available from the corresponding author on reasonable request.

\section{Authors' contributions}

JY and YK contributed to the concept and design of this study. JY analyzed the data, performed the statistical analyses, and wrote the manuscript. All authors have read and approved the manuscript.

\section{Authors' information}

Not applicable.

\section{Consent for publication}

Not applicable.

\section{Competing interest}


The authors declare that they have no conflict of interest.

\section{Ethical approval}

All procedures performed in studies involving human participants were in accordance with the ethical standards of the institutional and national research committee and with the 1964 Helsinki declaration and its later amendments or comparable ethical standards. This study was approved by the institutional review board of the two hospitals, and informed consent was obtained from all individual participants included in the study.

\section{Abbreviations}

HR: hormone receptor-positive (HR+); HER2-: human epidermal growth factor receptor 2-negative; CT: computed tomography; ER: estrogen receptor; PR: progesterone receptor; CEA: carcinoembryonic antigen; CA15-3: cancer antigen 15-3; OS: overall survival; DFI: disease-free interval; TTM: time to multiple metastases; $\mathrm{Cl}$ : confidence interval; HRs: hazard ratios

\section{References}

1. National Cancer Institute Surveillance, Epidemiology, and End Results Program. Cancer Statistics. Cancer Stat Facts: Female Breast Cancer. National Cancer Institute. 2019. http://seer.cancer.gov/statfacts/html/breast.html. Accessed 2 Oct 2019.

2. Hortobagyi GN, de la Garza Salazar J, Pritchard K, Amadori D, Haidinger R, Hudis CA, et al. The global breast cancer burden: variations in epidemiology and survival. Clin Breast Cancer. 2005;6:391-401.

3. Giuliani J, Bonetti A. Trends in survival for patients with metastatic breast cancer: is survival improving. Tumori. 2015;101:347-52.

4. Chung CT, Carlson RW. Goals and objectives in the management of metastatic breast cancer. Oncologist. 2003;8:514-20.

5. Harb WA. Management of patients with hormone receptor-positive breast cancer with visceral disease: challenges and treatment options. Cancer Manag Res. 2015;7:37-46.

6. Lobbezoo DJ, van Kampen RJ, Voogd AC, Dercksen MW, van den Berkmortel F, Smilde TJ, et al. Prognosis of metastatic breast cancer subtypes: the hormone receptor/HER2-positive subtype is associated with the most favorable outcome. Breast Cancer Res Treat. 2013;141:507-14.

7. National Comprehensive Cancer Network. NCCN clinical practice guidelines in oncology (NCCN Guidelines ${ }^{\circledR}$ ) with NCCN Evidence Blocks ${ }^{T M}$. 2019. https://www.nccn.org/EvidenceBlocks/. Accessed 8 Oct 2019.

8. Schnipper L, Davidson N, Wollins D, Blayney DW, Dicker AP, Ganz PA, et al. Updating the American Society of Clinical Oncology value framework: revisions and reflections in response to comments received. J Clin Oncol. 2016; 34:2925-34. 
9. Cardoso F, Senkus E, Costa A, Papadopoulos E, Aapro M, André F, et al. 4th ESO-ESMO International Consensus Guidelines for Advanced Breast Cancer (ABC 4). Ann Oncol. 2018;29:1634-57.

10. Le Saux O, Lardy-Cleaud A, Frank S, Debled M, Cottu PH, Pistilli B,et al. Assessment of the efficacy of successive endocrine therapies in hormone receptor-positive and HER2-negative metastatic breast cancer: a real-life multicentre national study. Eur J Cancer. 2019;118:131-41.

11. Yamamura J, Kamigaki S, Tsujie M, Fujita J, Osato H, Higashi C, et al. Response to First-line Recurrence Treatment Influences Survival in Hormone Receptor-positive, HER2-negative Breast Cancer: A Multicenter Study. In Vivo. 2019;33:281-7.

12. Bonotto M, Gerratana L, Di Maio M, De Angelis C, Cinausero M, Moroso S, et al. Chemotherapy versus endocrine therapy as first-line treatment in patients with luminal-like HER2-negative metastatic breast cancer: A propensity score analysis. Breast. 2017;31:114-20.

13. Xie J, Hao Y, Li N, Lin PL, Ohashi E, Koo V, et al. Clinical outcomes among HR+/HER2- metastatic breast cancer patients with multiple metastatic sites: a chart review study in the US. Exp Hematol Oncol. $2015 ; 4: 31$.

14. Rogoz B, Houzé de l'Aulnoit A, Duhamel A, Houzé de l'Aulnoit D. Thirty-Year Trends of Survival and Time-Varying Effects of Prognostic Factors in Patients With Metastatic Breast Cancer-A Single Institution Experience. Clin Breast Cancer. 2018;18:246-53.

15. Tsuji W, Teramukai S, Ueno M, Toi M, Inamoto T. Prognostic factors for survival after first recurrence in breast cancer: a retrospective analysis of 252 recurrent cases at a single institution. Breast Cancer. 2014;21:86-95.

16. Jung SY, Rosenzweig M, Sereika SM, Linkov F, Brufsky A, Weissfeld JL. Factors associated with mortality after breast cancer metastasis. Cancer Causes Control. 2012;23:103-12.

17. Largillier R, Ferrero JM, Doyen J, Barriere J, Namer M, Mari V, et al. Prognostic factors in 1,038 women with metastatic breast cancer. Ann Oncol. 2008;19:2012-9.

18. Andre F, Slimane K, Bachelot T, Dunant A, Namer M, Barrelier A, et al. Breast cancer with synchronous metastases: trends in survival during a 14-year period. J Clin Oncol. 2004;22:3302-8.

19. Watanabe J, Hayashi T, Tadokoro Y, Nishimura S, Takahashi K. Clinical pattern of primary systemic therapy and outcomes of estrogen receptor-positive, HER2-negative metastatic breast cancer: a review of a single institution. Breast Cancer Res Treat. 2017;166:911-7.

20. Llombart-Cussac A, Pivot X, Biganzoli L, Cortes-Funes H, Pritchard KI, Pierga JY, et al. A prognostic factor index for overall survival in patients receiving first-line chemotherapy for HER2-negative advanced breast cancer: an analysis of the ATHENA trial. Breast. 2014;23:656-62.

21. Cazzaniga M, Pronzato P, Leto di Priolo SL, De Matteis A, Di Costanzo F, Passalacqua R, et al. Patterns of relapse and modalities of treatment of breast cancer: the 'IRIS' Project, a multicenter observational study. Oncology. 2004;66:260-8.

22. Kwast AB, Voogd AC, Menke-Pluijmers MB, Linn SC, Sonke GS, Kiemeney LA, et al. Prognostic factors for survival in metastatic breast cancer by hormone receptor status. Breast Cancer Res Treat. 2014;145:503-11. 
23. Giordano SH, Buzdar AU, Smith TL, Kau SW, Yang Y, Hortobagyi GN. Is breast cancer survival improving? Cancer. 2004;100:44-52.

24. Wyld L, Gutteridge E, Pinder SE, James JJ, Chan SY, Cheung KL, et al. Prognostic factors for patients with hepatic metastases from breast cancer. Br J Cancer. 2003;89:284-90.

25. Harvey JM, Clark GM, Osborne CK, Allred DC. Estrogen receptor status by immunohistochemistry is superior to the ligand-binding assay for predicting response to adjuvant endocrine therapy in breast cancer. J Clin Oncol. 1999;17:1474-81.

26. Regierer AC, Wolters R, Ufen MP, Weigel A, Novopashenny I, Köhne $\mathrm{CH}$, et al. An internally and externally validated prognostic score for metastatic breast cancer: analysis of 2269 patients. Ann Oncol. 2014;25:633-8.

27. Newton PK, Mason J, Venkatappa N, Jochelson MS, Hurt B, Nieva J, et al. Spatiotemporal progression of metastatic breast cancer: a Markov chain model highlighting the role of early metastatic sites. NPJ Breast Cancer. 2015;1:15018.

28. Onken JS, Fekonja LS, Wehowsky R, Hubertus V, Vajkoczy P. Metastatic dissemination patterns of different primary tumors to the spine and other bones. Clin Exp Metastasis. 2019; doi.org/10.1007/s10585-019-09987-w.

29. Kennecke H, Yerushalmi R, Woods R, Cheang MC, Voduc D, Speers $\mathrm{CH}$, et al. Metastatic behavior of breast cancer subtypes. J Clin Oncol. 2010;28:3271-7.

30. Kast K, Link T, Friedrich K, Petzold A, Niedostatek A, Schoffer O, et al. Impact of breast cancer subtypes and patterns of metastasis on outcome. Breast Cancer Res Treat. 2015;150:621-9.

31. Turner NC, Finn RS, Martin M, Im SA, DeMichele A, Ettl J, et al. Clinical considerations of the role of palbociclib in the management of advanced breast cancer patients with and without visceral metastases. Ann Oncol. 2018;29:669-80.

\section{Tables}

Table 1 Patient characteristics 


\begin{tabular}{|c|c|c|c|c|c|}
\hline Characteristics & All & \multicolumn{3}{|c|}{ Single metastasis } & $\begin{array}{c}\text { Multiple } \\
\text { metastases }\end{array}$ \\
\hline Number & 271 & \multicolumn{3}{|c|}{$169(62 \%)$} & $102(38 \%)$ \\
\hline \multicolumn{6}{|l|}{ Stage at diagnosis } \\
\hline I & $37(14 \%)$ & \multicolumn{3}{|c|}{$24(14 \%)$} & $13(13 \%)$ \\
\hline IIA+IIB & $84+89(64 \%)$ & \multicolumn{3}{|c|}{$58+53(66 \%)$} & $62(61 \%)$ \\
\hline IIIA+IIIB+IIIC & $\begin{array}{c}32+22+7 \\
(22 \%)\end{array}$ & \multicolumn{3}{|c|}{$18+12+4(20 \%)$} & $27(26 \%)$ \\
\hline \multicolumn{6}{|l|}{ Adjuvant chemotherapy } \\
\hline Yes & $184(68 \%)$ & \multicolumn{3}{|c|}{$115(68 \%)$} & $69(68 \%)$ \\
\hline No & $87(32 \%)$ & \multicolumn{3}{|c|}{$54(32 \%)$} & $33(32 \%)$ \\
\hline $\begin{array}{l}\text { Median age at recurrence (range, } \\
\text { years) }\end{array}$ & $62(29-92)$ & \multicolumn{3}{|c|}{$62(29-90)$} & $63(33-92)$ \\
\hline $\begin{array}{l}\text { Median OS after recurrence (range, } \\
\text { years) }\end{array}$ & $\begin{array}{l}4.58(0.02- \\
13.53)\end{array}$ & \multicolumn{3}{|c|}{$5.86(0.04-13.53)$} & $2.50(0.02-12.21)$ \\
\hline DFI (median, years) & $\begin{array}{l}4.01(0.35- \\
16.85)\end{array}$ & \multicolumn{3}{|c|}{$3.98(0.58-12.02)$} & $4.04(0.35-16.85)$ \\
\hline$<2$ years & $56(21 \%)$ & \multicolumn{3}{|c|}{$35(21 \%)$} & $21(21 \%)$ \\
\hline$\geq 2$ years & 215 (79\%) & \multicolumn{3}{|c|}{$134(79 \%)$} & $81(79 \%)$ \\
\hline \multicolumn{6}{|l|}{ CEA/CA15-3 serum level } \\
\hline Normal & $106(47 \%)$ & \multicolumn{3}{|c|}{$81(57 \%)$} & $25(30 \%)$ \\
\hline High & $120(53 \%)$ & \multicolumn{3}{|c|}{$62(43 \%)$} & $58(70 \%)$ \\
\hline \multicolumn{6}{|l|}{ Initial therapy for reccurence } \\
\hline Endocrine therapy & $173(64 \%)$ & \multicolumn{3}{|c|}{$119(70 \%)$} & $54(53 \%)$ \\
\hline Chemotherapy & $83(31 \%)$ & \multicolumn{3}{|c|}{$42(25 \%)$} & $41(40 \%)$ \\
\hline unknown & $15(5 \%)$ & \multicolumn{3}{|c|}{$8(5 \%)$} & 7 (7\%) \\
\hline Metastatic organ site & & All & $\begin{array}{l}\text { Diffuse } \\
\text { lesions }\end{array}$ & $\begin{array}{l}\text { Non-diffuse } \\
\text { lesions }\end{array}$ & \\
\hline All & 271 & 169 & 90 (53\%) & $79(47 \%)$ & 102 \\
\hline Bone & 148 (55\%) & $\begin{array}{c}85 \\
(50 \%)\end{array}$ & $46(54 \%)$ & 39 (46\%) & $63(62 \%)$ \\
\hline Lymph node & $95(35 \%)$ & $\begin{array}{c}31 \\
(18 \%)\end{array}$ & $13(42 \%)$ & $18(58 \%)$ & $64(63 \%)$ \\
\hline Lung & $74(27 \%)$ & $\begin{array}{c}24 \\
(14 \%)\end{array}$ & 17 (71\%) & 7 (29\%) & $50(49 \%)$ \\
\hline Liver & $54(20 \%)$ & $14(8 \%)$ & $7(50 \%)$ & $7(50 \%)$ & $40(39 \%)$ \\
\hline Pleural & $41(15 \%)$ & $12(7 \%)$ & $6(50 \%)$ & $6(50 \%)$ & $29(28 \%)$ \\
\hline Brain & $8(3 \%)$ & $1(1 \%)$ & $1(100 \%)$ & $0(0 \%)$ & 7 (7\%) \\
\hline Others & $2(1 \%)$ & $2(1 \%)$ & $0(0 \%)$ & $2(100 \%)$ & $0(0 \%)$ \\
\hline
\end{tabular}

Table 2 Median overall survival (OS) after recurrence according to patient characteristics 


\begin{tabular}{|c|c|c|c|c|c|c|}
\hline \multirow[t]{2}{*}{ Characteristics } & \multicolumn{2}{|l|}{ All } & \multicolumn{2}{|c|}{ Single metastasis } & \multicolumn{2}{|c|}{ Multiple metastases } \\
\hline & $\begin{array}{l}\text { Median OS } \\
\text { (year) }\end{array}$ & $\begin{array}{c}\mathrm{p}- \\
\text { value }\end{array}$ & $\begin{array}{l}\text { Median OS } \\
\text { (year) }\end{array}$ & $\begin{array}{c}\mathrm{p}- \\
\text { value }\end{array}$ & $\begin{array}{l}\text { Median OS } \\
\text { (year) }\end{array}$ & $\begin{array}{c}\mathrm{p}- \\
\text { value }\end{array}$ \\
\hline All patients & 4.58 & & 5.86 & & 2.50 & $<0.001$ \\
\hline Stage at diagnosis & & 0.195 & & 0.840 & & 0.073 \\
\hline I+II & 4.60 & & 6.30 & & 2.53 & \\
\hline III & 3.79 & & 5.30 & & 1.78 & \\
\hline Adjuvant chemotherapy & & 0.446 & & 0.149 & & 0.613 \\
\hline Yes & 4.44 & & 5.46 & & 2.50 & \\
\hline No & 5.55 & & 7.56 & & 2.35 & \\
\hline Age at recurrence & & 0.972 & & 0.259 & & 0.596 \\
\hline$<50 y$ & 3.52 & & 4.54 & & 2.39 & \\
\hline$\geq 50 \mathrm{y}$ & 4.67 & & 6.81 & & 2.50 & \\
\hline DFI & & $<0.001$ & & $<0.001$ & & $<0.001$ \\
\hline$<2$ years & 2.17 & & 3.03 & & 1.35 & \\
\hline$\geq 2$ years & 5.33 & & 7.68 & & 3.26 & \\
\hline CEA/CA15-3 serum level & & $<0.001$ & & 0.014 & & 0.390 \\
\hline Normal & 8.20 & & 8.20 & & 3.54 & \\
\hline High & 3.26 & & 4.83 & & 2.49 & \\
\hline Initial therapy for reccurence & & 0.077 & & 0.348 & & 0.524 \\
\hline Endocrine therapy & 5.46 & & 6.30 & & 2.53 & \\
\hline Chemotherapy & 3.12 & & 5.30 & & 2.50 & \\
\hline $\begin{array}{l}\text { Distribution pattern in single } \\
\text { metastasis }\end{array}$ & & & & $<0.001$ & & \\
\hline Diffuse lesions & - & & 4.60 & & - & \\
\hline Non-diffuse lesions & - & & 11.83 & & - & \\
\hline Metastatic organ site & & & & & & \\
\hline Bone & 4.51 (vs. 4.83) & 0.443 & 5.86 (vs. 6.30) & 0.869 & 1.96 (vs. 3.26) & 0.327 \\
\hline Lymph node & 3.54 (vs. 5.46) & 0.022 & 4.54 (vs. 7.56) & 0.088 & 2.57 (vs. 2.20 ) & 0.279 \\
\hline Lung & 5.72 (vs. 4.54 ) & 0.688 & 8.20 (vs. 5.46) & 0.062 & 2.50 (vs. 2.44$)$ & 0.287 \\
\hline Liver & 1.96 (vs. 5.30) & $<0.001$ & 9.13 (vs. 5.72) & 0.670 & 1.88 (vs. 3.87) & $<0.001$ \\
\hline Pleura & 3.54 (vs. 4.73) & 0.204 & 2.90 (vs. 6.30 ) & 0.153 & 3.54 (vs. 2.39) & 0.254 \\
\hline Brain & 0.800 (vs. 4.67 ) & $<0.001$ & - & - & 0.800 (vs. 2.50 ) & 0.027 \\
\hline
\end{tabular}

Table 3 Univariate and multivariate analyses in patients with single metastatasis 


\begin{tabular}{|c|c|c|c|c|}
\hline \multirow{3}{*}{ Characteristics } & \multicolumn{4}{|c|}{ Single metastasis } \\
\hline & \multicolumn{2}{|c|}{ Univariate analysis } & \multicolumn{2}{|c|}{ Multivariate analysis } \\
\hline & HRs (95\%CI) & p-value & HRs (95\%CI) & p-value \\
\hline \multicolumn{5}{|l|}{ Stage at diagnosis } \\
\hline I+II & 1.00 & 0.840 & & \\
\hline III & $1.068(0.564-2.024)$ & & & \\
\hline \multicolumn{5}{|c|}{ Adjuvant chemotherapy } \\
\hline Yes & 1.00 & 0.152 & & \\
\hline No & $0.661(0.375-1.165)$ & & & \\
\hline \multicolumn{5}{|l|}{ Age at recurrence } \\
\hline$<50 y$ & 1.00 & & & \\
\hline$\geq 50 y$ & $0.726(0.415-1.270)$ & 0.261 & & \\
\hline \multicolumn{5}{|c|}{ CEA/CA15-3 serum level } \\
\hline Normal & 1.00 & & & \\
\hline High & $2.001(1.138-3.517)$ & 0.016 & $1.543(0.866-2.750)$ & 0.141 \\
\hline \multicolumn{5}{|l|}{ DFI } \\
\hline$<2$ years & $2.808(1.643-4.797)$ & $<0.001$ & $3.527(1.891-6.576)$ & $<0.001$ \\
\hline$\geq 2$ years & 1.00 & & & \\
\hline \multicolumn{5}{|c|}{ Initial therapy for reccurence } \\
\hline \multirow{2}{*}{$\begin{array}{l}\text { Endocrine therapy } \\
\text { Chemotherapy }\end{array}$} & 1.00 & 0.349 & & \\
\hline & $1.285(0.761-2.170)$ & & & \\
\hline \multicolumn{5}{|l|}{ Distribution pattern } \\
\hline Diffuse lesions & $2.922(1.699-5.025)$ & $<0.001$ & $3.641(1.856-7.141)$ & $<0.001$ \\
\hline Non-diffuse lesions & 1.00 & & & \\
\hline \multicolumn{5}{|l|}{ Metastatic organ site } \\
\hline Bone & $0.960(0.589-1.565)$ & 0.869 & & \\
\hline Lymph node & $1.678(0.919-3.067)$ & 0.092 & & \\
\hline Lung & $0.497(0.235-1.050)$ & 0.067 & & \\
\hline Liver & $1.221(0.488-3.055)$ & 0.670 & & \\
\hline Pleura & $1.927(0.770-4.831)$ & 0.161 & & \\
\hline Brain & - & - & & \\
\hline
\end{tabular}

Table 4 Univariate and multivariate analyses in patients with multiple metastases 


\begin{tabular}{|c|c|c|c|c|}
\hline \multirow[t]{3}{*}{ Characteristics } & \multicolumn{4}{|c|}{ Multiple metastases } \\
\hline & \multicolumn{2}{|c|}{ Univariate analysis } & \multicolumn{2}{|c|}{ Multivariate analysis } \\
\hline & HRs (95\%CI) & p-value & HRs (95\%CI) & p-value \\
\hline \multicolumn{5}{|l|}{ Stage at diagnosis } \\
\hline $\mathrm{I}+\mathrm{II}$ & 1.00 & 0.076 & & \\
\hline III & $1.695(0.946-3.030)$ & & & \\
\hline \multicolumn{5}{|c|}{ Adjuvant chemotherapy } \\
\hline Yes & 1.00 & 0.613 & & \\
\hline No & $1.151(0.667-1.989)$ & & & \\
\hline \multicolumn{5}{|l|}{ Age at recurrence } \\
\hline$<50 y$ & 1.00 & & & \\
\hline$\geq 50 y$ & $0.807(0.366-1.782)$ & 0.596 & & \\
\hline \multicolumn{5}{|c|}{ CEA/CA15-3 serum level } \\
\hline Normal & 1.00 & & & \\
\hline High & $1.337(0.688-2.595)$ & 0.391 & & \\
\hline \multicolumn{5}{|l|}{ DFI } \\
\hline$<2$ years & $3.229(1.768-5.895)$ & $<0.001$ & $3.082(1.669-5.694)$ & $<0.001$ \\
\hline$\geq 2$ years & 1.00 & & & \\
\hline \multicolumn{5}{|c|}{ Initial therapy for reccurence } \\
\hline Endocrine therapy & 1.00 & 0.524 & & \\
\hline Chemotherapy & $1.187(0.700-2.013)$ & & & \\
\hline \multicolumn{5}{|c|}{ Metastatic organ site } \\
\hline Bone & $0.769(0.455-1.301)$ & 0.328 & & \\
\hline Lymph node & $1.334(0.790-2.255)$ & 0.281 & & \\
\hline Lung & $0.757(0.452-1.266)$ & 0.289 & & \\
\hline Liver & $2.915(1.689-5.025)$ & $<0.001$ & $3.145(1.802-5.495)$ & $<0.001$ \\
\hline Pleura & $1.406(0.781-2.530)$ & 0.256 & & \\
\hline Brain & $2.532(1.078-5.952)$ & 0.033 & $3.289(1.355-7.937)$ & 0.008 \\
\hline
\end{tabular}

\section{Figures}


Single metastasis

Multiple metastases

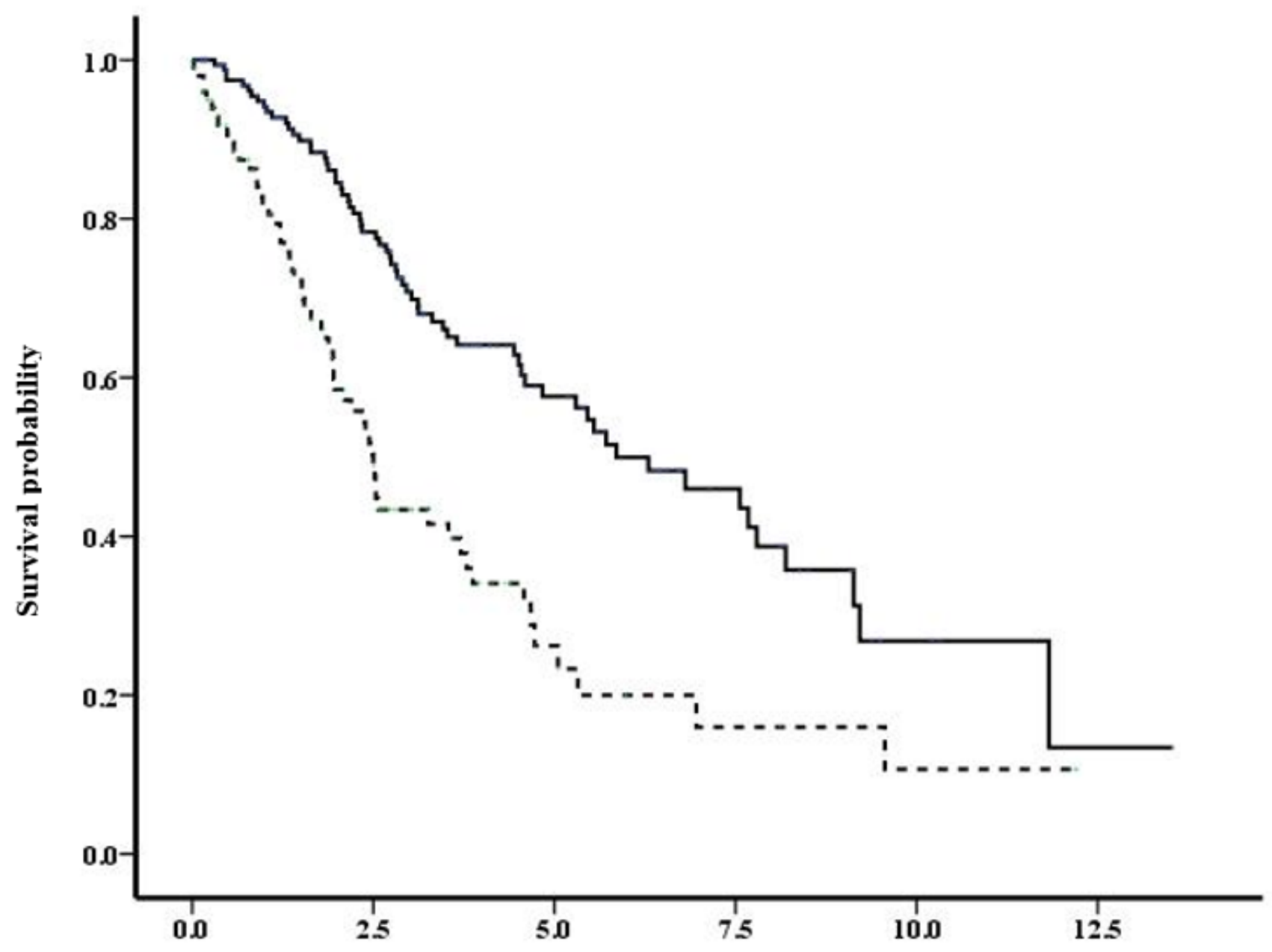

Years

Figure 1

Kaplan-Meier curve for survival after recurrence between single and multiple metastases $(p<0.001)$ 
a

Normal

High

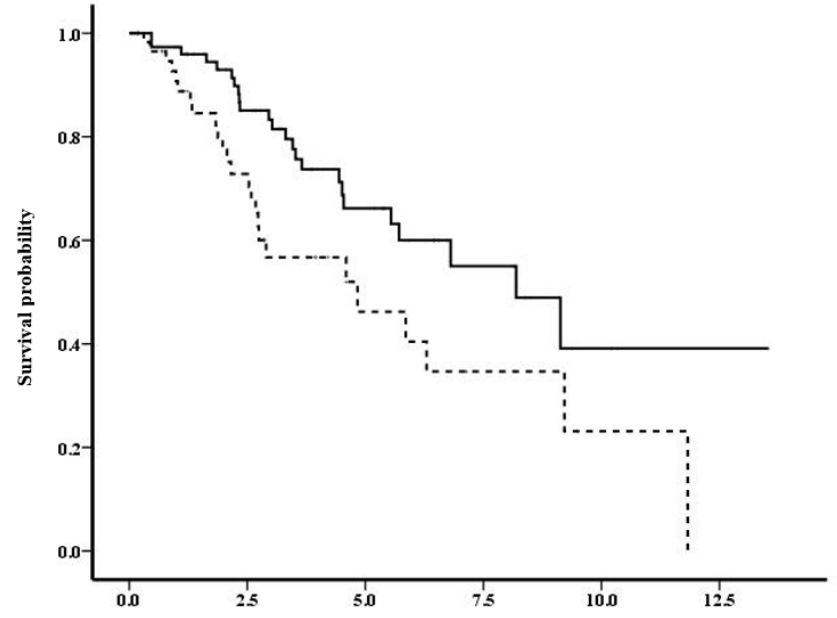

Years

c

Non-diffuse lesions

Diffuse lesions

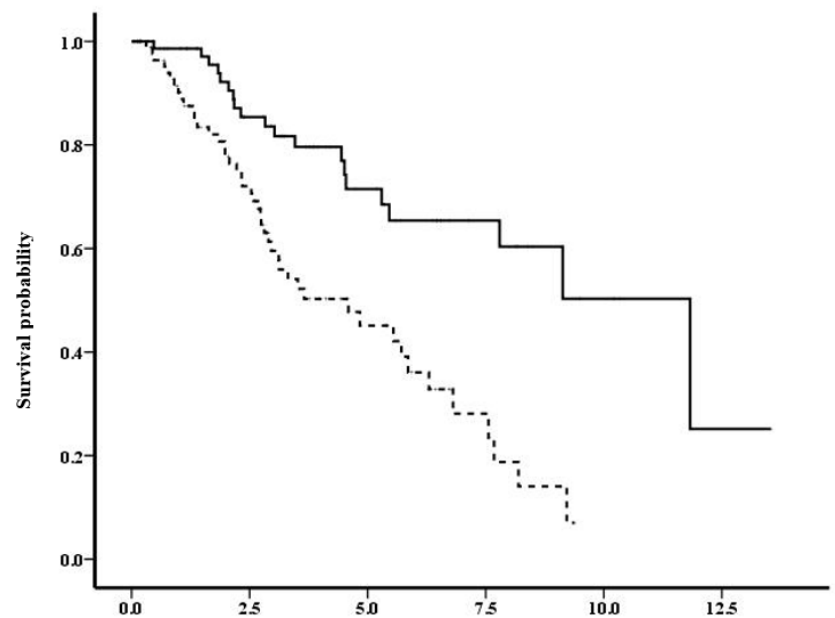

Years b

DFI $\geq 2 \mathrm{y}$

DFI $<2 y$

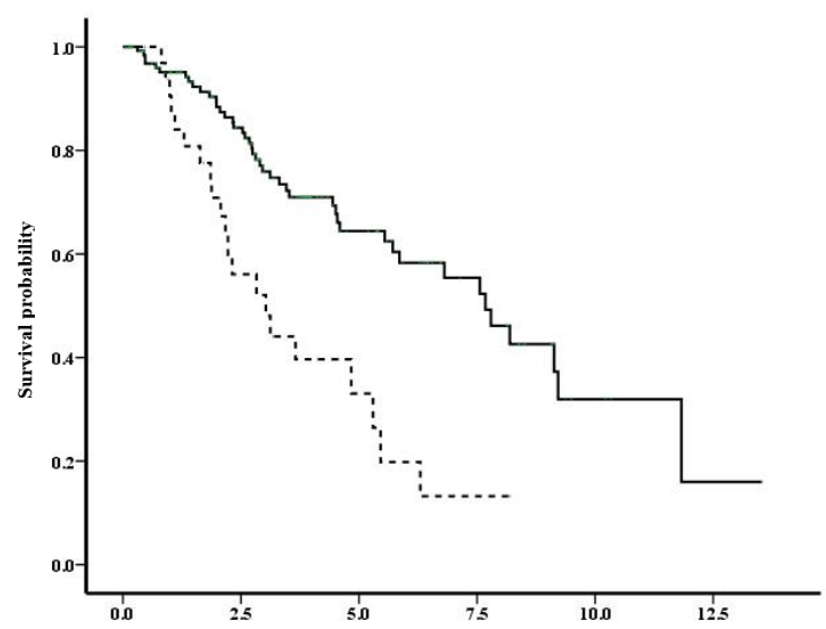

Years

\section{Figure 2}

Kaplan-Meier curves for survival after recurrence according to (a) serum CEA/CA15-3 levels in single metastasis ( $p=0.014)$, (b) DFI $<2$ years and $D F I \geq 2$ years in single metastasis $(p<0.001)$, and (c) diffuse lesions and non-diffuse lesions in single metastasis $(p<0.001)$ 
Non-diffuse lesions

Diffuse lesions

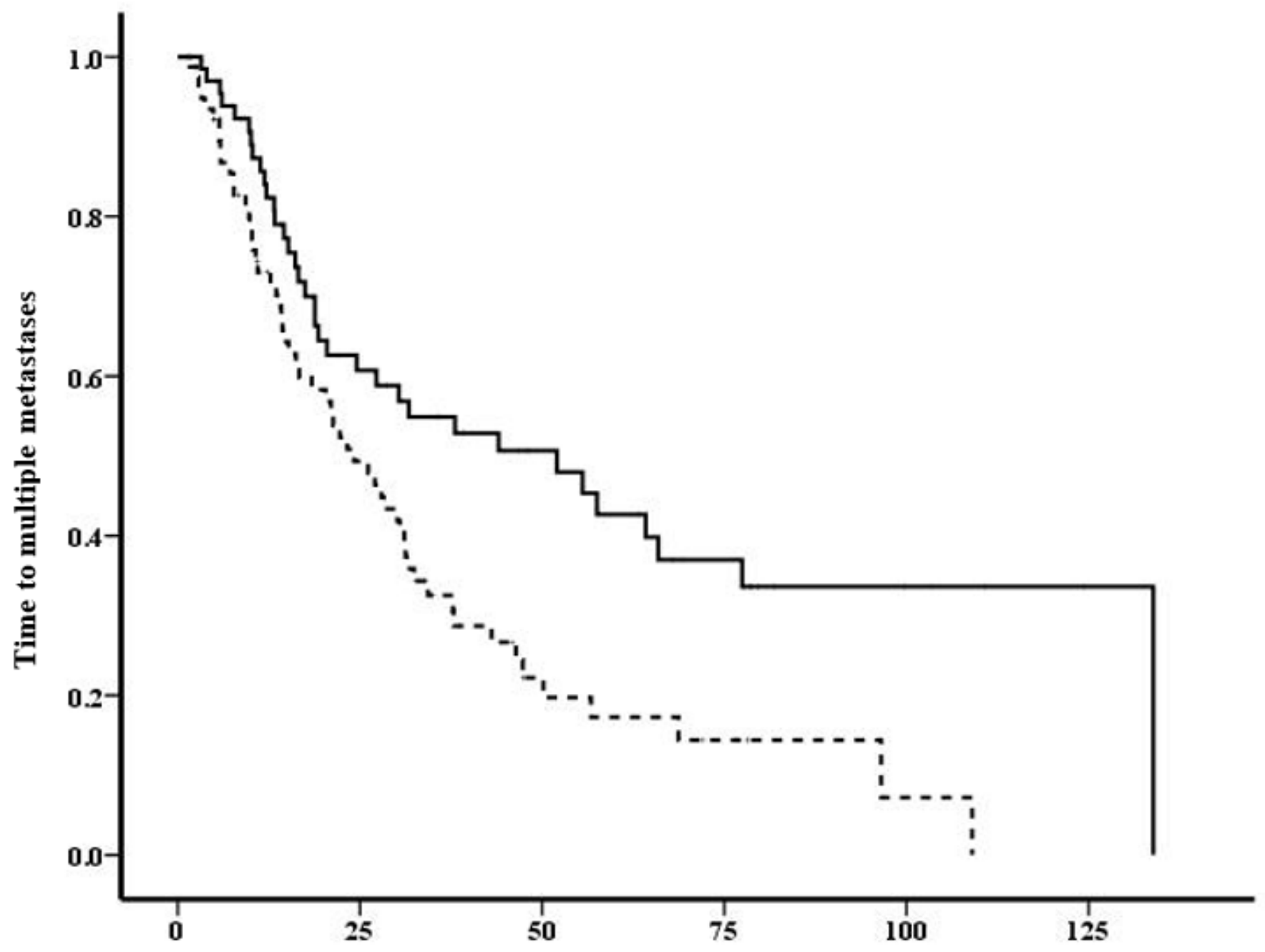

Months

Figure 3

Time to multiple metastases in patients with diffuse lesions and non-diffuse lesions in single metastasis $(p=0.002)$ 